\title{
Homeopathic treatment of ADHD/ADD: Increased Precision with Polarity Analysis of Perception Symptoms
}

\section{Heiner Frei*}

Swiss Association of Homeopathic Physicians and Institute for Complementary and Alternative Medicine, KIKOM, University of Berne, Switzerland

Submission: February 13, 2017; Published: August 13, 2018

*Corresponding author: Heiner Frei, Swiss Association of Homeopathic Physicians and Institute for Complementary and Alternative Medicine, KIKOM, University of Berne, Switzerland; Email: heiner.frei@hin.ch

\begin{abstract}
Summary
Attention Deficit Disorder with or without Hyperactivity (ADHD/ADD) is one of the difficult fields in pediatrics. Since the Swiss ADHD double-blind trial [1] has proved significant effects of homeopathy on impulsivity, attention deficit and hyperactivity/ passivity, the demand for this treatment has clearly increased. This paper introduces Polarity Analysis (PA), the method of remedy selection used in the study, which allows more precise matches between patient symptoms and homeopathic remedy, and leads in turn to better results. The procedure is demonstrated with a case history. Prospective outcome studies with short- and long term results in ADHD patients are included.

Keywords: Homeopathic treatment; ADHD/ADD; Hyperactivity; Polarity Analysis; Perception Symptoms; Conventional standard treatment is methylphenidate
\end{abstract}

Abbreviations: PA: Polarity Analysis; MPD: methylphenidate; CGI: Conners Global Index; ORG: Organon

\section{Introduction}

ADHD/ADD consists of the main symptoms hyperactivity or passivity, impulsivity, and impaired attention [2]. It has been diagnosed with increasing frequency since the 1990s. Conventional standard treatment is methylphenidate (MPD), an amphetamine derivative that is subject to narcotics legislation in most countries. In Switzerland the consumption of MPD was $10 \mathrm{~kg}$ in 1996 whereas by 2011 it had increased to $349 \mathrm{~kg}$, and there is no foreseeable reduction in this upwards trend [3]. Many parents are uneasy with administering such powerful medication to their children and seek other treatments, especially homeopathy.

\section{Conventional Homeopathic Treatment of ADHD/} ADD

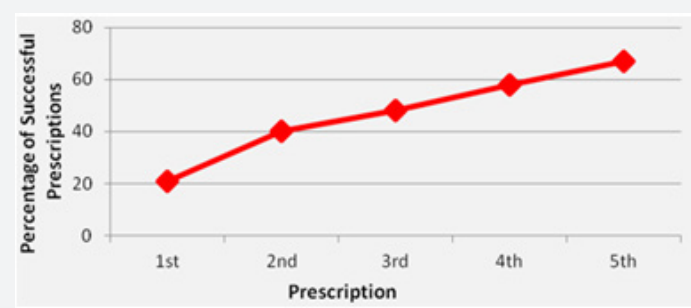

Figure 1: Conventional Homeopathic Treatment in ADHD/ADD: Percentage of Successful Prescriptions $(n=86)$.
In contrast to other illnesses, it is usually difficult to elicit reliable symptoms for remedy determination in ADHD/ADD because the symptom set is often dominated by stereotypical complaints, while the characteristic disturbances of perception go unnoticed. Our treatment results with a conventional homeopathic procedures were chastening. Figure 1 illustrates these difficulties.

Table 1: Unreliable Symptoms in 100 ADHD / ADD Cases.

\begin{tabular}{|c|c|}
\hline Mind symptoms and their modalities & 44 \\
\hline General modalities & 11 \\
\hline Perception symptoms & 4 \\
\hline Motor symptoms & 6 \\
\hline Food symptoms (desires, dislikes, modalities) & 6 \\
\hline Weather modalities & 6 \\
\hline
\end{tabular}

Several attempts were usually needed to find the most suitable remedy. In order to improve the precision of our prescriptions, we analysed the symptom set of 100 successfully treated patients, who initially received ineffective remedies. The aim was to find out which symptoms had prevented a correct prescription on first attempt. The result was sobering: 77 symptoms, almost everything that we used so far for remedy 
selection, were found to be potentially unreliable, including many mind symptoms (Table 1) [4].

\section{The Significance of Perception Symptoms}

In the search for more reliable symptoms we began to experiment with perception symptoms. Perception disorders are the pathophysiological cause of ADHD/ADD: The peripheral perception organs function normally, whereas the selection of stimuli, their processing and the reaction to them are disturbed, which leads to restlessness, poor concentration, rapid fatigue and maladjusted behaviour [5]. Impaired perception can affect sight, hearing, smell, touch, temperature sensitivity and proprioception. Secondary effects are speaking disorders, inadequate fine and gross motor skills, slow thinking, weak memory and mind symptoms such as sadness and irritability.

Table 2: Questionnaire for Perception Disorders and ADHD/ADD.

\begin{tabular}{|c|c|}
\hline Symptom & Interpretation \\
\hline \multicolumn{2}{|r|}{ High Reliabilty } \\
\hline Light in general: worse & Easily dazzled, ask for sunglasses \\
\hline Looking at something close-up: worse & Restless, irritability after consumption of electronic media, TV, PC, etc. \\
\hline Reading: worse & Tire quickly from reading, dislike reading \\
\hline Talking: worse & Speech disturbance \\
\hline Touch: worse & Dislike touch, find touch unpleasant \\
\hline Warmth, in general: worse & Often feel too warm \\
\hline Warmth of room: worse & Restless, irritability in overheated rooms \\
\hline Uncovering: better & Quick to undress and to uncover themselves \\
\hline Cold, in general: worse & Freeze quickly \\
\hline Uncovering: worse & Quickly feel cold, put on lots of clothes, want to cover up \\
\hline Movement, aversion to & Inactive \\
\hline Writing; worse & Write or draw in cramped way, tire quickly, dislike drawing \\
\hline Sleep, after, on awaking: worse & Irritable, restless after sleep, trouble getting going in the morning \\
\hline Sleep, before: worse & Irritable, restless in evening, when tired, before sleep \\
\hline Understanding difficult & Difficulty understanding complex issues \\
\hline Sadness & Downcast, weepy \\
\hline Irritability & $\begin{array}{l}\text { Aggressive, fits of rage we found what we were looking for. we found what we were looking } \\
\text { for. }\end{array}$ \\
\hline Muscles tense (must be veryfied by physician) & Basic muscle tone high \\
\hline Muscles flabby (must be veryfied by physician) & Basic muscle tone low \\
\hline \multicolumn{2}{|r|}{ Intermediate Reliability } \\
\hline Noises: worse & Cannot tolerate noise from other people \\
\hline Hearing hypersensitive & React to sounds that do not disturb other people \\
\hline Smell hypersensitive & Oversensitive to smells, smell things everywhere \\
\hline Taste diminished & Add sauce or spices to many foods \\
\hline Traveling in vehicle: worse & Nausea or headache when traveling in a car \\
\hline Movement, desire for & Excessive desire for sports [Distinguish this symptom from straightforward restlessness.] \\
\hline Movement: better & More relaxed and even-tempered after sports \\
\hline
\end{tabular}

To achieve an improvement, it was necessary to identify symptoms in Boenninghausens Therapeutic Pocketbook (PB 1846) [6], that are related to disturbed perception. Evaluating the success rate of remedy selection by perception symptoms, we found that the number of suboptimal remedies given prior to the optimal one dropped from the previous four to two [7]. Yet we also saw that not all perception symptoms are equally reliable. Table 2 shows the actual questionnaire for perception disorders and $A D H D / A D D$, with highly reliable symptoms in the upper section and symptoms of intermediate reliability in the lower one. We use the second category only if there is a lack of highly reliable symptoms.

The back side of the questionnaire contains all the symptoms that have proved unreliable (see: www.heinerfrei.ch). We do not include them in the repertorization. The individual combination of perception deficits allows a precise remedy determination in ADHD/ADD.

We always supplement case-taking with the Questionnaire for Additional Complaints where the parents list disorders unrelated 
to ADHD/ADD. It is relatively common to find there additional perception symptoms that can be included in the repertorization. Further symptoms are only used when the perception symptoms don't permit an accurate remedy selection. The homeopathic remedy for ADHD/ADD normally brings about a substantial general improvement, and the additional complaints often disappear too. Yet the restriction to reliable symptoms can also result in a lack of information, such that too many remedies remain for the differential diagnosis. With polarity analysis it is generally possible to overcome this problem.

\section{Polarity Analysis}

Polarity Analysis (PA) is a new method of remedy determination, based on the grading of the symptoms of Boenninghausens Therapeutic Pocketbook (PB 1846). It consists of the elements polarity difference and contraindications, which are explained below [8]. PA enabled us to demonstrate in the Swiss ADHD double-blind study a significant difference between placebo and homeopathic remedies [1]. Later on, the evaluation studies of acute, chronic and complex illness invariably revealed improved results in comparison with conventional homeopathic procedures $[8,9]$.

\section{Boenninghausens Contraindications}

Hahnemann established in the Organon (ORG) § 133 that the modalities show the peculiar and characteristic aspects of each symptom [10]. In combination with ORG $§ 153$, this means that homeopathic remedy selection in particular ought to be determined by the modalities.

Boenninghausen himself strived to match the patient's characteristic symptoms with the "genius of a homeopathic remedy". The genius of a remedy includes its characteristic symptoms, with modalities, sensations and findings observed in provings in various localizations. Genius symptoms must also have been healed by the remedy to deserve this qualification. In the PB 1846 they are listed with a high grade (3-5).

The concept of contraindications concerns polar symptomsthose which have an opposite pole, such as: thirst / thirstlessness, cold aggravates / cold ameliorates, desire for fresh air / dislike of fresh air. The patients symptom can only correspond to one pole of a polar symptom. But a remedy can cover both poles, due to the fact that its symptoms are observations of several provers. Normally one pole of the polar symptom is in a high grade, i.e. what is typical for the remedy; the other in a low grade, i.e. what is nonspecific to the remedy. Because the patient's symptoms should correspond to the genius of the remedy, Boenninghausen strived to match them at as high a grade as possible. If the remedy contained the patient's symptom at a low grade (12 ) but the opposite pole of the same symptom at a high grade (3-5), he regarded this as a contraindication for the remedy. According to his experience, such a constellation rarely led to healing. The Polarity Analysis Software identifies remedies with contraindications by marking them with a gray background [11].

\section{Polarity difference}

The polarity difference is a new concept. To calculate it, the software adds for each remedy the grades of the patient's polar symptoms and then subtracts the grades of their opposite poles. The higher the polarity difference, the more likely the remedy corresponds to the patient's characteristic symptoms. With other words: The higher the sum of grades of the patient symptoms, and the smaller the sum of grades of their opposite poles, the higher is the similarity between patient symptoms and remedy.

To elicit polar symptoms homeopathic case-taking is supplemented with checklists for acute illness and questionnaires for chronic illness. Here the patients underline the symptoms that they have observed. So far eight checklists and twelve questionnaires have been developed for different problem areas, such as neurology, gynecology, ENT and airways, gastroenterology, musculo-skeletal system, and so on [9] (see also: www.heinerfrei.ch).

\section{Case-Taking Procedure}

Homeopathic case-taking for chronic illness requires two sessions. During the first consultation, a brief case history is taken and the patient is examined. Then the treatment and the prospects of success are explained, and the parents are introduced to the questionnaires for Disturbances of Perception and $A D H D / A D D$, and Additional Complaints as well as the form for $A D H D / A D D$ Assessment, which is designed to record the success of the treatment. Here the parents must evaluate the ten most important symptoms on a scale of intensity from 0 to 3 -first before treatment starts, and then again at every check-up. The symptoms are: excitable and impulsive / cries easily and often / restless, fidgety / restless, always on the go / destructive / lack of stamina / poor concentration / rapid mood changes / easily frustrated / disturbs other children. It is derived from the Conners Global Index (CGI), an instrument widely used in conventional medicine for the assessment of MPD treatments [12]. When discussing the course of treatment, it is important to alert parents to the fact that treatment takes time and the prospects of success improve with increasing duration. By the second consultation the parents are expected to have filled out the questionnaires as carefully as possible. We discuss the symptoms they noted and perform the repertorization. - With this procedure one normally arrives at a small group of remedies. For the final selection we look at the hight of the polarity difference and search for confirmatory symptoms in the materia medica.

\section{Confirmatory Symptoms}

According to ORG $\S 211$, “... the patient's emotional state often tips the scales in the selection of the homeopathic remedy." Kent taught that remedy selection should be especially orientated to the mind symptoms. However, "tips the scales" does not mean that mind symptoms are the best source of information. The original meaning of ORG $§ 211$ was different: after determining the likely remedies on the basis of characteristic symptoms (especially the 
modalities), the changes in mind can be decisive for final selection of the remedy (see also ORG $\S 216$ and 218). Table 3 contains a list of possible confirmatory symptoms for the remedies frequently found in ADHD/ADD.

Table 3: Confirmatory Symptoms.

\begin{tabular}{|c|c|c|}
\hline Remedy & Frequency in percent & Keynotes \\
\hline Calcium carbonicum & 14 & $\begin{array}{c}\text { Fearful, shy, obstinate, < consolation when sad, flabby muscles, profuse sweating, late } \\
\text { teething, exhaustion }\end{array}$ \\
\hline Lycopodium & 11 & Tyrannical behaviour in familiar situations, poor sense of self-worth \\
\hline Sulphur & 10 & Dislike of washing, foul-smelling excretions, skin problems, < warmth of bed \\
\hline Nux vomica & 6 & Irritable, ambitious, put themselves under stress, fits of rage, impatient, oversensitive \\
\hline Phosphorus & 6 & $<$ Being alone, short attention span, fearful, weak \\
\hline Causticum & 5 & Intense emotions, cannot bear to see others suffer, rebellious, compulsion to control \\
\hline Ignatia & 5 & $\begin{array}{l}\text { Oversensitive, vulnerable, upset, < consolation when sad, anticipatory tension, changes in } \\
\text { mood }\end{array}$ \\
\hline Silicea & 4 & $\begin{array}{l}\text { Remote, obstinate, conscientious, }<\text { consolation when sad, disturbances of mineralization, } \\
\text { tendency to suppurate }\end{array}$ \\
\hline Mercurius solubilis & 4 & Mistrustful, reserved, impulsive, bad breath, < nights \\
\hline Belladonna & 4 & Irritable, < consolation when sad, febrile delirium, convulsions, inner heat, dysmenorrhea \\
\hline Chamomilla & 4 & Irritable, fits of rage with hitting, sensitivity to pain \\
\hline Sepia & 4 & Very demanding, indifferent, withdrawn, < consolation when sad, < company \\
\hline Hepar sulphur & 3 & Irritable, sensitivity to pain, foul-smelling excretions, delayed wound healing \\
\hline China & 3 & $\begin{array}{l}\text { Irritable, sensitivity of all sensory organs, high-expectations in dreams of future, periodicity } \\
\text { of complaints }\end{array}$ \\
\hline Lachesis & 2 & Jealous, talkative, fits of rage, sarcasm, < heat, < touching neck \\
\hline Phosphoricumacidum & 2 & Indifferent, slow replies, exhausted, < upset \\
\hline Pulsatilla & 2 & Gentle, weepy, need comforting, changes of mood, < heat, > outdoors \\
\hline Staphysagria & 2 & $\begin{array}{l}\text { Complaints from suppression of sorrow and anger, fits of rage, throws objects around, < } \\
\text { consolation when sad }\end{array}$ \\
\hline Arsenicum album & 1 & Anxious, perfectionist, restless, < after midnight, < being alone, fear of illness and infection \\
\hline Natrum muriaticum & 1 & Taciturn, < worry, < insult, resentful, > being alone, < consolation when sad \\
\hline Magnetispolusarcticus & $<1$ & Fearful apprehension, self-reproaches, want to do everything quickly, overcareful \\
\hline Aconitum & $<1$ & Complaints from psychological shock, fear in crowds, < dry cold \\
\hline Aurum & $<1$ & Melancholy, fits of rage, dictatorial behaviour, fear of failure \\
\hline Arnica & $<1$ & Overexertion, effects of injuries (physical and mental) \\
\hline
\end{tabular}

\section{Results of the Optimization Process}

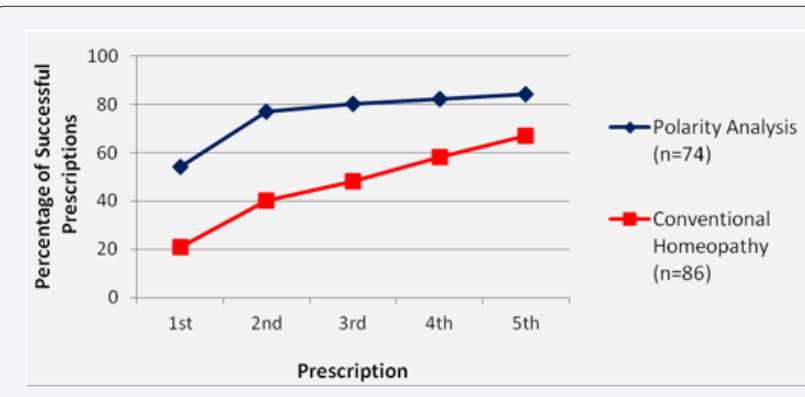

Figure 2: shows the strong positive effect of the entire optimization process on treatment results.

In summary, we have taken the following steps to optimize the treatment of ADHD/ADD:

1. Identification and avoidance of unreliable symptoms.
2. Remedy selection with the help of perception symptoms.

3. Polarity Analysis for an optimal match between symptoms and remedy.

4. Questionnaires to ensure careful observation of polar symptoms (Figure 2).

\section{A Case study}

Matthias is a thin 9 year old boy with hypotonia of the muscles, dark hair and dark skin. At school he is restless with a short attention span, clumsy and absolutely passiv at times. His thinking and understanding is slow, especially concerning abstract matters, and he has a poor memory. Due to dyslexia he receives special teaching. Since early childhood Matthias has suffered from fear of the dark and has poor selfconfidence, yet at home he is dictatorial towards his mother and 
brother, especially since his parents separated three years ago. Following a comprehensive neurological and neuropsychological examination, he is diagnosed with ADHD. Since his mother does not want him to take MPD, she comes for a homeopathic consultation.

In the Questionnaire for Disturbances of Perception, ADHD/ $A D D$, she underlined the following symptoms:

\section{High reliability}

a) Strained vision (looking at something close up): worse - $\mathrm{P}^{*}$

b) Touch, worse - $\mathrm{P}$

c) Warmth, worse - P

d) Uncovering, better - P

e) Writing, worse - P

f) Sleep, before, worse - P

g) Understanding difficult - P

h) Irritable, aggressive, fits of rage - $\mathrm{P}$ i) Muscles, flabbiness - $\mathrm{P}$

\section{Intermediate reliability}

a) Noises, worse

b) Sense of smell, hypersensitive - $\mathrm{P}$

c) Sense of taste, reduced

d) Memory, weak

* $\mathrm{P}=$ polar symptoms

On the Questionnaire for Additional Complaints, she also mentions abdominal pain and extreme irritability when hungry. Matthias prefers frequent but small meals. His mother rates his CGI with 17 points (moderately severe ADHD). For the repertorization we only use highly reliable polar perception symptoms, including the symptom muscles flabby because it was verified in the examination.

\section{Key}

Repertorization chart: Below the blue bar: patient's symptoms. Below the red bar: opposite polar symptoms (Figure $3)$.

\section{Matthias A.}

ADHS

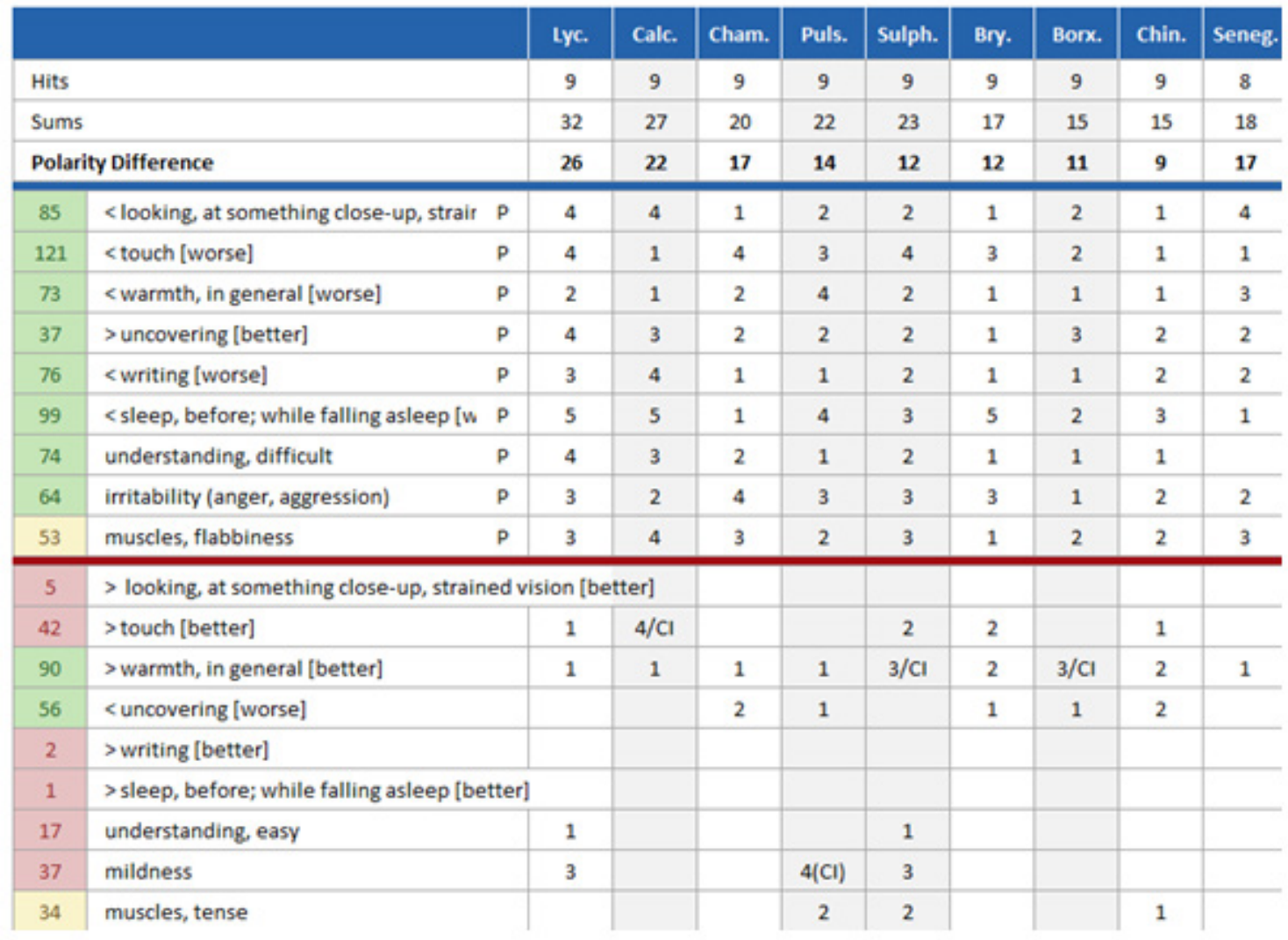

Figure 3: Repertorization (Polarity Analysis Software) [11]. 
Colors mark symptom reliability: Green= high, yellow=intermediate, red=low.

Definition of Contraindications CI: The opposite pole is found at a high grade (3-5) whereas the patient's symptom is found at a low grade (1-2). The opposite pole therefore corresponds to the genius of the remedy, not the patient's symptom. Let's take Borax for example: the patient's symptom of warmth aggravates is found at grade 1 whereas the opposite pole warmth ameliorates is found at grade 3. Warmth ameliorates is therefore the genius symptom of the remedy, which is therefore contraindicated. Remedies with contraindications are indicated by grey shading.

Polarity difference: To calculate the polarity difference we add the grades of the polar symptoms for each remedy and subtract from the result the grades of the opposite poles. For example Borax: 15-4 = 11. The higher the polarity difference, the more the remedy corresponds to the patient's characteristic symptoms.

Eight remedies cover all symptoms, but only four of these have no contraindications. Due to the hight of the polarity difference the best candidates are Lycopodium and Chamomilla. The additional complaints such as dictatorial behaviour coupled with a lack of self-confidence, and irritability when skipping a meal are a prominent confirmatory symptoms for Lycopodium.

\section{Prescription and progress}

Matthias is given Lycopodium Q3 daily. After four weeks things are going better at school. Matthias has begun to read books, which he never used to do, and he is reading more fluent. He calms down quickly after arguments and upsets, and his CGI has dropped from 17 to 15 . Although this is not much, we decide to continue with Lycopodium Q6. For the next two weeks, he is very irritable before calming down again. But he starts writing a diary for the first time in his life. A month later the mother still has a good feeling about Lycopodium: Despite fits of rage and oppositional behaviour her son listens better to her, and the CGI has fallen to 14. Another month later, after Lycopodium Q9, she says he is very sweet now, can listen properly and calms down immediately after arguments. His CGI has dropped to 8. This trend continues in the long term, and his CGI eventually stabilizes at 7 points (Figure 4).

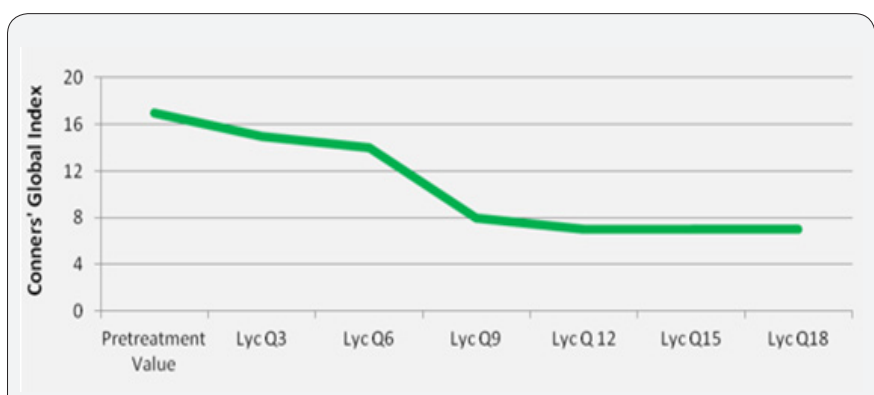

Figure 4: M.H. CGI Improvement under Homeopathic Treatment.

\section{Treatment Results of Polarity Analysis in ADHD/ ADD Patients}

In our practice we treated in 2012417 children with ADHD and ADD. Of these 357 (85.6\%) used only homeopathy, 45 (10.8\%) MPD and 15 (3.6\%) Atomoxetine. In the homeopathy group, 90 children $(25 \%)$ were given Q-potencies, all others received single doses at average intervals of four weeks (potencies 200C, 1M,10M, 50M and 100M). Many patients had already been in homeopathic treatment for several years. Those who did not improve sufficiently with homeopathy were transferred to treatment with either MPD or Atomoxetine. The most common reason for conventional treatment was school pressure (Figure 5).

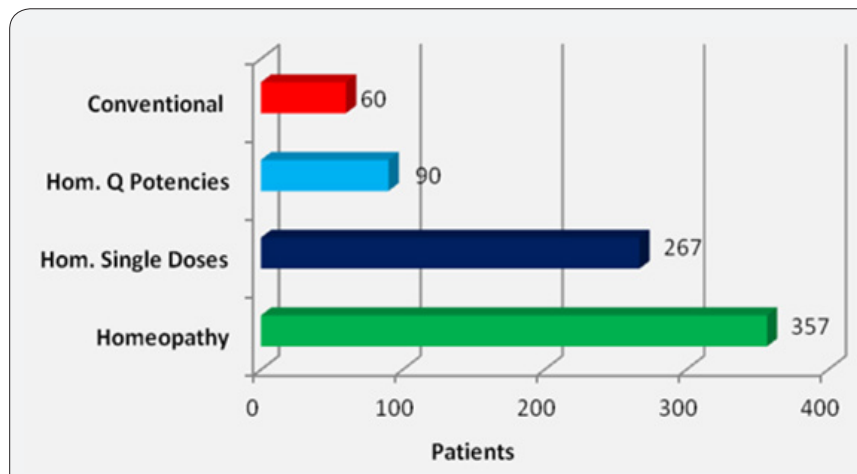

Figure 5: ADHD/ADD Treatment in our Practice $2012(n=417)$.

In 40 newly admitted patients, the progress of the improvement as reflected by the CGI was prospectively recorded over 12 months. With homeopathy the CGI dropped on average in 32 of the 40 patients ( $80 \%$, responders) from 18 to 7 . This is an improvement of $61 \%$. In the remaining 8 patients $(20 \%$, nonresponders) we did not achieve a sustained improvement (Figure 6).

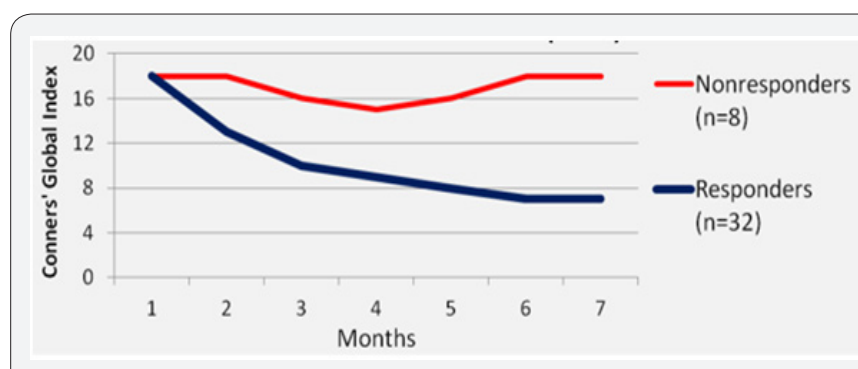

Figure 6: Treatment Results of new ADHD/ADD Patients in our Practice $2012(n=40)$.

At the end of the Swiss ADHD/ADD trial, parents and patients were free to choose with what type of treatment they would like to continue. Five years after the start of treatment, 60 of the 62 study participants were available for a long-term follow-up. Twentyeight children were still treated with homeopathy: their CGI averaged 6,8. Twentyfive children had stopped all treatment: their CGI averaged 8,8 and seven children had switched to MPD: their CGI averaged 10.6 (Figure 7). 


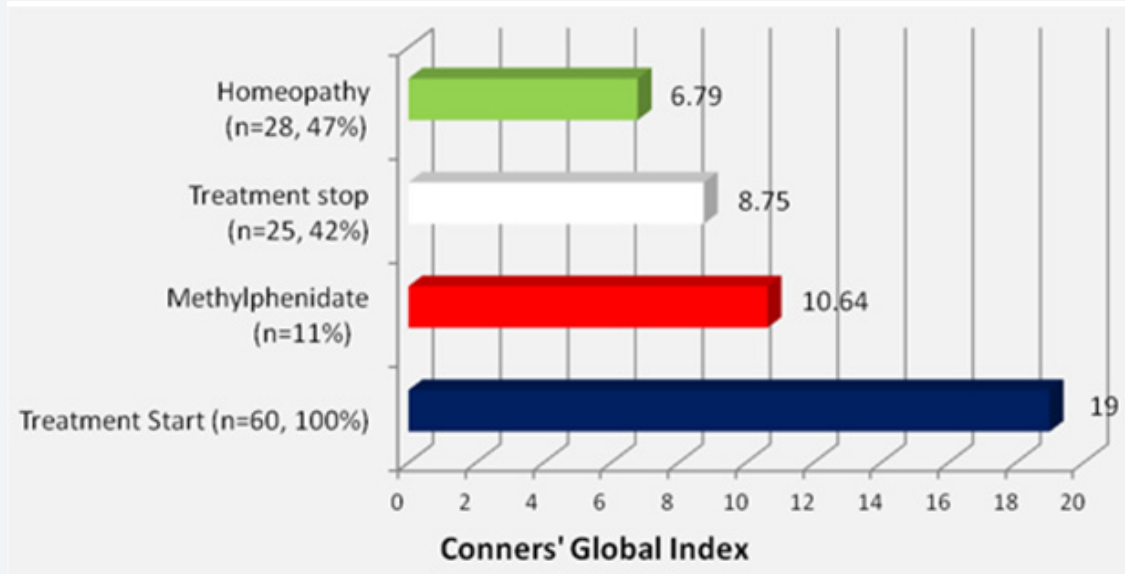

Figure 7: State of ADHD Treatment 5 years after Start, CGI-Longtime Values $(n=60)$.

\section{Discussion}

The Swiss ADHD/ADD double-blind study, which was completed twelve years ago, provided proof of a significant effect of highly diluted homeopathic remedies. Equally important in this study was the discovery of polarity analysis, which was responsible for the successful outcome. Meanwhile this method has been further refined and successfully tested in other fields like acute and chronic disease and multimorbid patients. Possible obstacles for successful treatment have been identified. To obtain optimal results the following rules must be observed:

a) In ADHD/ADD not all perception symptoms are highly reliable for remedy selection; if possible avoid those of intermediate reliability.

b) Do not mix Polarity Analysis with another homeopathic procedure: this is a frequent beginner's mistake.

c) Unsuccessful treatment is very often characterized by poor observation of symptoms. Careful instruction of the patients and parents is a crucial prerequisite.

d) It is possible that the approximately $20 \%$ nonresponders are due to the limited number of 125 remedies covered by the PB 1846 . One can counter the problem by relying on knowledge of the materia medica or by using another repertory in cases where we might expect a remedy not listed. Overall the advantages of the PB 1846, most especially the high level of reliability in remedy grading, are so substantial that the author of this paper would never like to work without it.

Despite some hurdles, and with patience and perseverance, we can achieve very gratifying results in most of our ADHD/ADD patients. This brings great relief to the child, the family and the school, allowing the child to live a normal life once more.

\section{Textbooks}

Frei H: Homeopathy and ADHD - A New Treatment Concept with Polarity Analysis. Narayana Publishers, Kandern, 2015.
Frei H: Polarity Analysis in Homeopathy, A Precise Path to the Simillimum, Kandern: Narayana Publishers, 2013.

\section{Software}

Frei H, Hubele J, Polarity Analysis Software, based on Boenninghausens Therapeutic Pocketbook 1846. Austin 2016 (http://polarity-analysis.com).

\section{References}

1. Frei H, Everts R, von Ammon K et al (2005) Homeopathic Treatment in Children with Attention Deficit Hyperactivity Disorder - a Randomized, Double-Blind, Placebo Controlled Trial. Eur J Ped 164: 758-767.

2. (1994) American Psychiatric Association: Diagnostic and Statistical Manual of Mental Disorders, $4^{\text {th }}$ ed. Washington DC: American Psychiatric Association.

3. Stricker HR (2013) Der Ritalinkonsum in der Schweiz steigt weiter an. Schweiz. Ärztezeitung 94(15): 575-577.

4. Frei H, von Ammon K, Thurneysen A (2006) Treatment of Hyperactive Children: Increased Efficiency through Modifications of Homeopathic Diagnostic Procedure. Homeopathy. Homeopathy (2006) 95(6): 163170.

5. Ayres AJ (1972) Sensory Integration and Learning Disorders, Los Angeles: Western Psychological Services.

6. Boenninghausen Cv (2014) Boenninghausens Therapeutic Pocketbook. Edited by TF Allen. Reprint by Jain Publishers New Delhi.

7. Frei H (2015) Homeopathy and ADHD - A New Treatment Concept with Polarity Analysis. Narayana Publishers, Kandern, 2015.

8. Frei H (2009) Polarity analysis, a new approach to increase the precision of homeopathic prescriptions. Homeopathy 98(1): 49-55.

9. Frei H (2013) Polarity Analysis in Homeopathy, A Precise Path to the Simillimum, Kandern: Narayana Publishers.

10. Hahnemann S (1996) The Organon of the Medical Art, (6 $6^{\text {th }}$ ed). Transl. S. Decker, ed. W.B. O’Reilly. Redmond, WA: Birdcage Books.

11. Frei H, Hubele J (2016) Polarity Analysis Software, based on Boenninghausens Therapeutic Pocketbook 1846. Austin.

12. Conners CK (1997) Conners Rating Scales - Revised. Multi Health Systems, Toronto. 
This work is licensed under Creative Commons Attribution 4.0 License DOI: 10.19080/JCMAH.2018.06.555692

\section{Your next submission with Juniper Publishers} will reach you the below assets

- Quality Editorial service

- Swift Peer Review

- Reprints availability

- E-prints Service

- Manuscript Podcast for convenient understanding

- Global attainment for your research

- Manuscript accessibility in different formats

( Pdf, E-pub, Full Text, Audio)

- Unceasing customer service

Track the below URL for one-step submission https://juniperpublishers.com/online-submission.php 